\title{
草甘膦对加拿大一枝黄花和伴生植物白茅种间竞 争关系的影响
}

\section{古春凤 ${ }^{1,2}$ 叶小齐 ${ }^{2}$ 吴 明 ${ }^{*}$ 邵学新 ${ }^{2}$ 焦盛武 ${ }^{2}$}

${ }^{1}$ 杭州师范大学生命与环境科学学院, 杭州 310036; ${ }^{2}$ 中国林业科学研究院亚热带林业研究所, 国家林业局杭州湾湿地生态系统定位观测研究站, 浙江 富阳 311400

摘 要 大量使用草甘膦防除外来植物将会改变入侵植物与邻近植物之间的相互关系。该文通过分析不同浓度草甘膦对植物 生长和种间竞争关系的影响, 以揭示除草剂作用下植物种间关系的变化规律, 为进一步研究草甘膦的生态效应提供理论参 考, 为优化农药使用提供数据支持。2016年6至8月, 在国家林业局杭州湾湿地生态系统定位观测研究站, 采用盆栽控制试验 方法, 将入侵植物加拿大一枝黄花(Solidago canadensis)和土著植物白茅(Imperata cylindrica)分别进行单独种植和混种种植, 喷施7种浓度的草甘膦后测定植物的生长特征。结果显示: 草甘膦处理显著抑制了加拿大一枝黄花和白茅的生长。随着草甘 膦处理浓度升高, 加拿大一枝黄花的株高增长量明显降低、绿叶数不断减少, 0.3-1.5 mL $\cdot \mathrm{L}^{-1}$ 处理组单种、混种加拿大一枝黄 花的绿叶数均随时间呈递增趋势, 而 $1.8 \mathrm{~mL} \cdot \mathrm{L}^{-1}$ 处理单种、混种加拿大一枝黄花基本枯菱死亡; 白茅的分藥死亡数和枯萎叶片 长均随草甘膦处理浓度递增而不断增长, $0.3-0.6 \mathrm{~mL} \cdot \mathrm{L}^{-1}$ 处理组单种、混种白茅分藥数和绿叶长度随时间呈增加趋势。草甘膦 处理显著影响植物种间竞争关系, 随着处理浓度上升, 混种加拿大一枝黄花和白茅之间的竞争关系不断减弱。种间竞争关系 显著影响了加拿大一枝黄花的生物量分配, 面对竞争时加拿大一枝黄花将更多的生物量分配到根部, 因而增加了根冠比; 种 间竞争抑制了白茅分摹数的增加和生物量的积累, 但不影响其植株生物量的分配。草甘膦处理和种间关系的交互作用同样显 著影响加拿大一枝黄花和白茅生物量的增加, 但对两种植物根冠比的影响均不显著。结果表明: 不同植物对草甘膦的耐受性 不同, 与本土植物白茅相比, 生长能力强的入侵植物加拿大一枝黄花对草甘膦处理具有更强的耐受性; 低浓度草甘膦处理减 弱了两种植物之间的竞争关系, 可能会干扰入侵地植物群落的结构和动态。

关键词 除草剂; 入侵植物; 本地植物; 生长; 种间关系

引用格式: 古春风, 叶小齐, 吴明, 邵学新, 焦盛武 (2017). 草甘膦对加拿大一枝黄花和伴生植物白茅种间竞争关系的影响. 植物生态学报, 41, 439-449. doi: 10.17521/cjpe.2016.0331

\section{Effects of glyphosate on interspecific competition between Solidago canadensis and Imperata cylindrica}

GU Chun-Feng ${ }^{1,2}$, YE Xiao-Qi², WU Ming ${ }^{2 *}$, SHAO Xue-Xin², and JIAO Sheng-Wu ${ }^{2}$

${ }^{1}$ College of Life and Environment Sciences, Hangzhou Normal University, Hangzhou 310036, China; and ${ }^{2}$ Research Institute of Subtropical Forestry, Chinese Academy of Forestry, Wetland Ecosystem Research Station of Hangzhou Bay, State Forestry Administration, Fuyang, Zhejiang 311400, China

\section{Abstract}

Aims The extensive use of herbicide to control invasive plants would change the relationship between alien and neighboring plants. In order to provide data for rational use of herbicide and a theoretical reference for further studies on the ecological effects of glyphosate, we explored the variation of the relationship between an invasive plant Solidago canadensis and a native plant Imperata cylindrica when they were sprayed glyphosate.

Methods A replacement series experiment was conducted from June to August 2016 in Wetland Ecosystem Research Station of Hangzhou Bay, State Forestry Administration, to examine the effects of glyphosate at seven concentration levels $\left(0,0.3,0.6,0.9,1.2,1.5,1.8 \mathrm{~mL} \cdot \mathrm{L}^{-1}\right)$ on the growth and interspecific competition of $S$. canadensis and I. cylindrica.

Important findings (1) Glyphosate treatment significantly inhibited the growth of S. canadensis and I. cylindrica $(p<0.05)$. During the test, cumulative growth of height and leaf number of $S$. canadensis were apparently reduced with the increase of glyphosate concentration, but the leaf number of $S$. canadensis treated with $0.3-$

收稿日期Received: 2016-10-27 接受日期Accepted: 2017-02-28

* 通信作者Author for correspondence (E-mail: hangzhoubay@126.com) 
$1.5 \mathrm{~mL} \cdot \mathrm{L}^{-1}$ glyphosate was re-growing with time, while the one treated with $1.8 \mathrm{~mL} \cdot \mathrm{L}^{-1}$ was mostly dead. The withering rate of tiller and green leaf of $I$. cylindrica also significantly increased with the increase of glyphosate concentration, and the growth indices of this plant treated with $0.3-0.6 \mathrm{~mL} \cdot \mathrm{L}^{-1}$ were also re-growing with time. (2) Glyphosate treatment significantly affected interspecific competition $(p<0.05)$, which diminished as the glyphosate concentration increased. (3) Interspecific competition has significant influence on the biomass allocation of $S$. canadensis $(p<0.05)$. When facing competition, $S$. canadensis would allocate more organic matter to root and thus increase the ratio of root to shoot. Competition only inhibited the tiller number and total biomass of $I$. cylindrica, but insignificantly affected its ratio of root to shoot. (4) The interaction between glyphosate treatment and $S$. canadensis-I. cylindrica interspecific relationship also significantly influenced the biomass of $S$. canadensis and I. cylindrica $(p<0.05)$, but insignificantly affected the root/shoot ratio of two plants. Different plants have different tolerance to glyphosate stress. Compared with native plant I. cylindrica, S. canadensis has stronger tolerance to glyphosate. Low-concentration glyphosate could decrease the competitive intensity between $S$. canadensis and I. cylindrica, which may disturb the structure and dynamics of plant communities.

Key words herbicide; invasive plant; native plant; growth; interspecific relationship

Citation: Gu CF, Ye XQ, Wu M, Shao XX, Jiao SW (2017). Effects of glyphosate on interspecific competition between Solidago canadensis and Imperata cylindrica. Chinese Journal of Plant Ecology, 41, 439-449. doi: 10.17521/cjpe.2016.0331

随着全球变化加剧以及我国对外经济的发展, 外来植物的入侵频率和危害程度正在迅速增加，现 已成为我国重大环境问题(鞠瑞亭等, 2012; Pan et al., 2015)。入侵植物严重威胁了入侵地的生物多样 性, 干扰了原生态系统的结构, 甚至引起生态系统 服务功能退化, 造成我国每年超过70亿美元的经济 损失(黄乔乔等, 2012)。防治外来植物普遍使用化学 防除、人工拔除等方法(强胜, 2009)。有的学者提议 利用替代植被抵御外来植物入侵或者引进天敌以恢 复稳定的生态平衡(徐正浩和王一平, 2004; Funk et al., 2008; 张瑞海, 2010), 这类生物防治法具有控制 效果持久、对环境安全等优点, 但仍需要长期评估 其生态风险性, 因此并未被大面积采用(强胜等, 2010); 由于人工拔除法存在成本过高的缺点, 目前 我国防治外来植物主要依赖于经济、高效的化学防 除法。自然条件下, 植物种内或种间普遍存在相互 作用(Maestre et al., 2009), 正、负相互作用的动态平 衡对植物群落结构和生态系统功能稳定有重要影响 (Callaway, 2002; Brooker, 2008)。当受到环境胁迫或 者生物因素影响时, 植物邻体之间的相互作用将会 发生变化(Maestre et al., 2009; He et al., 2013; Zhang et al., 2013)。大量使用化学除草剂防除外来植物、 抑制植物生长发育的同时, 必然直接或间接改变植 物物种之间的相互联系(Brooker, 1998; Weidenhamer, 2010), 由此可能干扰植物群落的自然演替, 破坏当地生态系统的动态平衡。

加拿大一枝黄花(Solidago canadensis)为菊科一 枝黄花属(Solidago)的多年生草本植物, 原产于北美,
20世纪初作为观赏花卉引进我国上海、南京等地, 随后迅速向外扩散蔓延, 广泛入侵华东沿海湿地生 态系统, 现已成为我国十大恶性杂草之一(董梅等, 2006; 陆彦等, 2006)。白茅(Imperata cylindrica)是多 年生根茎禾草, 是常见的生长于河岸滩涂湿地的优 势草本植物, 其植被的存在能够修复和改善脆弱的 土壤环境, 有利于维持生态系统的稳定(白世红等, 2010)。长期观察发现, 在国家林业局杭州湾湿地生 态系统定位观测研究站(以下简称观测站)邻近区域, 加拿大一枝黄花自然入侵到土著白茅群落, 并有不 断向外蔓延的趋势。加拿大一枝黄花繁殖和抗逆境 能力强, 入侵初期先与土著植物伴生, 随后抢占大 量生存资源, 不断排挤土著植物而成为优势植物 种(杨如意等, 2011; Gusev, 2015), 严重损害了入侵 地的植物多样性、威胁原生态系统的稳定, 因此有 必要采取措施防止加拿大一枝黄花的进一步入侵 扩散。

草甘膦因理化性质稳定，具有高效、低毒等优 点, 是目前被大量使用的除草剂(Duke \& Powles, 2008; 周垂帆等, 2013)。但目前对草甘膦影响入侵 植物的研究主要集中在草甘膦的防除效果(陆彦等, 2006; Duke \& Powles, 2008; 杨柳青等, 2011)、草甘 膦对目标植物生理的影响 (Lydon \& Duke, 1988; Guo et al., 2009; 李光义等, 2010), 以及抗性或非抗 性植物对草甘膦的敏感性(陈景超等, 2011; 刘文娟 等, 2012)等方面, 草甘膦处理是否会影响植物之间 相互作用及其机理还有待深入研究。为此, 本研究 以国家林业局杭州湾湿地公园内自然入侵的加拿大

www.plant-ecology.com 
一枝黄花和常见伴生植物白茅为研究对象, 设计了 盆栽控制试验, 研究喷施草甘膦后加拿大一枝黄花 与其伴生植物种间相互作用的变化规律, 为进一步 研究草甘膦的生态效应提供理论参考, 为优化农药 使用提供数据支持。

\section{1 材料和方法}

\section{1 供试材料}

加拿大一枝黄花和白茅均具有极强的繁殖能 力, 能以种子和根状茎两种方式进行繁殖, 在野外, 这两种植物一般通过克隆繁殖产生大量植株, 不断 地向四周扩散蔓延。生长季结束时, 无性繁殖器官 根状茎存储了大量营养物质用于下一个生长季新生 幼苗的生长。因此, 2016年3月初在国家林业局杭州 湾湿地公园 $\left(121.15^{\circ} \mathrm{E}, 30.31^{\circ} \mathrm{N}\right)$ 采集试验所用的加 拿大一枝黄花和白茅, 将采回植物的地下茎分别剪 至2-3 cm长度, 使地下茎对两种植物单株的影响基 本一致。以当地土壤为基质, 栽种于观测站大棚内 继续生长。

根据预试验的试验结果确定药剂的浓度范围, 将 $41 \%$ 的草甘膦异丙胺盐水剂(中化作物保护品有 限公司，上海)配制成7种不同浓度的水溶液。

\section{2 试验设计}

于2016年6-8月在观测站大棚内进行试验, 试 验过程中日平均气温为 $28.2{ }^{\circ} \mathrm{C}$, 平均空气湿度为 $74 \%$ 。选取生长良好、长势相当的加拿大一枝黄花 和白茅植株, 移栽于口径 $23 \mathrm{~cm}$ 、深 $17 \mathrm{~cm}$ 的塑料花 盆内进行盆栽试验。

试验设计采取替代系列试验(彭恒等, 2010; 周 建等, 2015), 种植方式为加拿大一枝黄花单独种 植、白茅单独种植、加拿大一枝黄花和白茅混合种 植, 每盆种植 4 株植物(混种时, 两个物种比例为 $1: 1$ ); 草甘膦浓度为 $0 \mathrm{~mL} \cdot \mathrm{L}^{-1}$ (对照)、0.3 $\mathrm{mL} \cdot \mathrm{L}^{-1} 、 0.6$ $\mathrm{mL} \cdot \mathrm{L}^{-1} 、 0.9 \mathrm{~mL} \cdot \mathrm{L}^{-1} 、 1.2 \mathrm{~mL} \cdot \mathrm{L}^{-1} 、 1.5 \mathrm{~mL} \cdot \mathrm{L}^{-1} 、 1.8$ $\mathrm{mL} \cdot \mathrm{L}^{-1}$, 分别用 $\mathrm{G} 0 、 \mathrm{G} 0.3 、 \mathrm{G} 0.6 、 \mathrm{G} 0.9 、 \mathrm{G} 1.2 、 \mathrm{G} 1.5$ 和G1.8表示, 共21个处理, 每个处理7个重复, 共 147盆。以当地土壤为基质, 植物适应性生长 3 周, 于 2016年6月12日, 用直尺(精确度为 $0.1 \mathrm{~cm}$ ) 测量每株 加拿大一枝黄花的株高, 统计其绿叶数、黄叶数和 枯萎叶数, 记录每株白茅的分莧数、每叶片长度, 随 后用喷雾器对每盆植株均匀喷施不同浓度的草甘膦 各 $5 \mathrm{~mL}$ 。施药后每间隔20天左右(7月4日、7月26日、
8月17日)对各草甘膦浓度处理下每株植株的形态指 标进行测定和记录。加拿大一枝黄花和白茅生长 60 天后, 记录各处理下植株的死亡数, 然后将所有植 株连根拔起, 用自来水将根系的泥土冲洗干净、晾 干, 装入信封后放入烘箱, 在 $105{ }^{\circ} \mathrm{C}$ 杀青 $30 \mathrm{~min}$, 于 $65{ }^{\circ} \mathrm{C}$ 烘干至恒质量, 分别测定地上和地下部分生物 量。试验期间每20天更换花盆摆放位置, 以减少环 境差异可能带来的实验误差。

\section{3 数据处理}

以每个处理 7 个重复植株测量值的平均值来代 表该处理结果。先采用双因素方差分析法分析草甘 膦处理浓度和植物生长方式(混种、单种)及两者交 互作用对植物生长(形态指标、生物量、根冠比)的 影响; 以草甘膦浓度为自变量, 对加拿大一枝黄花 和白茅的各个生长指标(包括株高、绿叶数、分藥数、 绿叶片长、生物量、根冠比)进行单因素方差分析, 用最小显著差异法 $(L S D)$ 对不同草甘膦浓度之间的 差异进行多重比较; 然后对单种、混种下各种生长 指标进行独立样本 $t$ 检验。

以加拿大一枝黄花和白茅的干质量为指标, 采 用相对产量 $(R Y)$ 这一指标来衡量不同浓度草甘膦处 理下加拿大一枝黄花和白茅种间竞争强度(Williams \& McCarthy, 2001), 其计算公式为:

$$
R Y=Y_{\mathrm{ab}} / Y_{\mathrm{a}}
$$

公式(1)中, $\mathrm{a} 、 \mathrm{~b}$ 分别代表两种植物, $Y_{\mathrm{a}}$ 表示植物 $\mathrm{a}$ 在单 种时每株植物生物量的平均值, $Y_{\mathrm{ab}}$ 表示植物 $\mathrm{a}$ 在混 种时每株植物生物量的平均值。当 $R Y=1.0$ 时, 表示 两种植物种内和种间竞争强度相同; 当 $R Y<1.0$ 时, 表示种间竞争强度比种内竞争强度大; 当 $R Y>1.0$ 时, 则表示种内竞争强度比种间竞争强度大(黄赦 等, 2012; 周建等, 2015)。计算出两种植物的 $R Y$ 值, 采用单因素方差分析检验草甘膦处理浓度对植物种 间关系的影响。数据处理采用Excel 2013软件完成, 采用SPSS 19.0软件对实验数据进行方差分析和差 异显著性检验, 所有图形采用SigmaPlot 12.5软件绘 制完成。

\section{2 结果和分析}

\section{1 草甘膦处理对加拿大一枝黄花和白茅生长的 影响}

从表 1 可以看出, 当草甘膦作用 60 天后, G0.6的 单种加拿大一枝黄花、白茅和混种白茅开始出现死 
表1 不同浓度草甘膦处理下加拿大一枝黄花和白茅植株的累计死亡率(平均值土标准误差)

Table 1 Plant mortality rate of Solidago canadensis and Imperata cylindrica treated with different concentrations of glyphosate (mean \pm SE)

\begin{tabular}{|c|c|c|c|c|}
\hline \multirow{2}{*}{$\begin{array}{l}\text { 草甘膦处理 } \\
\text { Glyphosate } \\
\text { treatment }\end{array}$} & \multicolumn{4}{|c|}{ 植株死亡率 Plant mortality rate (\%) } \\
\hline & $\begin{array}{l}\text { 单种加拿大一枝黄花 } \\
\text { S. canadensis grown in monoculture }\end{array}$ & $\begin{array}{l}\text { 混种加拿大一枝黄花 } \\
\text { S. canadensis grown in mixture }\end{array}$ & $\begin{array}{l}\text { 单种白茅 } \\
\text { I. cylindrica grown in monoculture }\end{array}$ & $\begin{array}{l}\text { 混种白茅 } \\
\text { I. cylindrica grown in mixture }\end{array}$ \\
\hline G0 & $0.00 \pm 0.00^{\mathrm{aA}}$ & $0.00 \pm 0.00^{\mathrm{aA}}$ & $0.00 \pm 0.00^{\mathrm{aA}}$ & $0.00 \pm 0.00^{\mathrm{aA}}$ \\
\hline G0.3 & $0.00 \pm 0.00^{\mathrm{aA}}$ & $0.00 \pm 0.00^{\mathrm{aA}}$ & $0.00 \pm 0.00^{\mathrm{aA}}$ & $0.00 \pm 0.00^{\mathrm{aA}}$ \\
\hline G0.6 & $14.28 \pm 10.71^{\mathrm{aA}}$ & $0.00 \pm 0.00^{\mathrm{aB}}$ & $14.29 \pm 9.22^{\mathrm{bA}}$ & $14.29 \pm 9.22^{\mathrm{aA}}$ \\
\hline G0.9 & $7.14 \pm 4.61^{\mathrm{aA}}$ & $7.14 \pm 7.14^{\mathrm{aA}}$ & $39.29 \pm 12.02^{\mathrm{bA}}$ & $7.14 \pm 7.14^{\mathrm{aA}}$ \\
\hline G1.2 & $25.00 \pm 14.43^{\mathrm{abA}}$ & $0.00 \pm 0.00^{\mathrm{aB}}$ & $71.43 \pm 12.71^{\mathrm{cA}}$ & $50.00 \pm 15.43^{\mathrm{bA}}$ \\
\hline G1.5 & $21.43 \pm 8.50^{\mathrm{abA}}$ & $50.00 \pm 10.91^{\mathrm{bA}}$ & $89.29 \pm 7.43^{\mathrm{CA}}$ & $57.14 \pm 14.86^{\mathrm{bcB}}$ \\
\hline G1.8 & $46.43 \pm 14.86^{\mathrm{bA}}$ & $64.29 \pm 14.28^{\mathrm{bA}}$ & $92.86 \pm 7.14^{\mathrm{CA}}$ & $85.71 \pm 9.2^{\mathrm{bA}}$ \\
\hline
\end{tabular}

G0、G0.3、G0.6、G0.9、G1.2、G1.5和 $\mathrm{G} 1.8$ 分别表示草甘膦浓度为 $0 \mathrm{~mL} \cdot \mathrm{L}^{-1} 、 0.3 \mathrm{~mL} \cdot \mathrm{L}^{-1} 、 0.6 \mathrm{~mL} \cdot \mathrm{L}^{-1} 、 0.9 \mathrm{~mL} \cdot \mathrm{L}^{-1} 、 1.2 \mathrm{~mL} \cdot \mathrm{L}^{-1} 、 1.5 \mathrm{~mL} \cdot \mathrm{L}^{-1} 、 1.8 \mathrm{~mL} \cdot \mathrm{L}^{-1}$ 。 同列不同小写字母表示不同处理浓度之间差异显著 $(p<0.05)$; 同行不同大写字母表示不同种植方式之间差异显著。

G0, G0.3, G0.6, G0.9, G1.2, G1.5 and G1.8 represent $0,0.3,0.6,0.9,1.2,1.5$ and $1.8 \mathrm{~mL} \cdot \mathrm{L}^{-1}$ glyphosate, respectively. The different lowercase letters in each column indicate that there were significant differences among different concentrations $(p<0.05)$; the different uppercase letters in each row indicate that there were significant differences between different plant modes.

亡植株; G1.2处理下, 白茅的死亡植株比例急剧升 高，混种白茅的植株死亡率达 $50 \%$ ，单种白茅的植 株死亡率则达到 $71 \%$; 在G1.8处理下，加拿大一枝 黄花也出现大量植株死亡的现象, 单种加拿大一枝 黄花的死亡率已到 $46 \%$, 混种加拿大一枝黄花的死 亡率则达到64\%。直到试验结束时, 最高浓度处理 (G1.8)组加拿大一枝黄花、白茅植株并未全部死亡, 故仍然收集所有处理下的植株进行相关统计分析。

草甘膦处理显著抑制了加拿大一枝黄花和白 茅的形态指标 $(p<0.05$, 表2)。7种浓度草甘膦处理
后0-60天, 加拿大一枝黄花和白茅形态指标的变化 见图1和图2。随着草甘膦处理浓度的升高, 加拿大 一枝黄花的株高增长明显不断受到抑制; 随着处理 时间的延长，与对照相比, G0.3、G0.6、G0.9处理下 单种、混种加拿大一枝黄花株高仍有增加, 但增加 速率明显逐渐降低; 而G1.2、G1.5、G1.8处理下加 拿大一枝黄花基本停止株高增长。加拿大一枝黄花 能进行光合作用的绿叶片数同样随处理浓度递增而 不断减少，但随处理时间的延长, G0.3、G0.6、G0.9 (20-60天)和G1.2、G1.5 (40-60天)处理下，草甘膦对

表2 种植方式和草甘膦处理对加拿大一枝黄花和白茅生长指标的影响

Table 2 Effects of planting method and glyphosate treatment on the growth of Solidago canadensis and Imperata cylindrica

\begin{tabular}{|c|c|c|c|c|c|c|}
\hline \multirow[t]{2}{*}{ 生长指标 Growth index } & \multicolumn{2}{|c|}{ 种植方式 Planting method } & \multicolumn{2}{|c|}{ 草甘膦处理 Glyphosate treatment } & \multicolumn{2}{|c|}{ 交互作用 Interaction } \\
\hline & $F$ & $p$ & $F$ & $p$ & $F$ & $p$ \\
\hline \multicolumn{7}{|l|}{ 加拿大一枝黄花 S. canadensis } \\
\hline 总生物量 Total biomass & 69.695 & $0.000^{* *}$ & 20.433 & $0.000^{* *}$ & 2.965 & $0.011^{*}$ \\
\hline 地上生物量 Aboveground biomass & 82.594 & $0.000^{* *}$ & 20.185 & $0.000^{* *}$ & 0.473 & $0.030^{*}$ \\
\hline 地下生物量 Underground biomass & 22.363 & $0.000^{* *}$ & 11.761 & $0.000^{* *}$ & 2.881 & $0.013^{*}$ \\
\hline 株高 Plant height & 18.520 & $0.000^{* *}$ & 18.010 & $0.000^{* *}$ & 3.000 & $0.010^{*}$ \\
\hline 绿叶数 Green leaf number & 0.604 & 0.439 & 11.192 & $0.000^{* *}$ & 1.621 & 0.151 \\
\hline 根冠比 Root /shoot ratio & 6.773 & $0.011^{*}$ & 0.826 & 0.553 & 1.643 & 0.145 \\
\hline 植株死亡率 Plant mortality rate & 0.012 & 0.912 & 11.057 & $0.000^{* *}$ & 2.336 & $0.039^{*}$ \\
\hline \multicolumn{7}{|l|}{ 白茅 I. cylindrica } \\
\hline 总生物量 Total biomass & 37.776 & $0.000^{* *}$ & 37.701 & $0.000^{* *}$ & 7.802 & $0.000^{* *}$ \\
\hline 地上生物量 Aboveground biomass & 32.195 & $0.000^{* *}$ & 29.126 & $0.000^{* *}$ & 5.642 & $0.000^{* *}$ \\
\hline 地下生物量 Underground biomass & 36.954 & $0.000^{* *}$ & 36.851 & $0.000^{* *}$ & 8.675 & $0.000^{* *}$ \\
\hline 分薬数 Tiller number & 13.195 & $0.000^{* *}$ & 50.831 & $0.000^{* *}$ & 5.75 & $0.000^{* *}$ \\
\hline 绿叶长度 Length of green leaf & 1.379 & 0.244 & 52.523 & $0.000^{* *}$ & 1.254 & 0.288 \\
\hline 根冠比 Root/shoot ratio & 0.615 & 0.435 & 0.599 & 0.730 & 2.357 & 0.058 \\
\hline 植株死亡率 Plant mortality rate & 5.242 & $0.025^{* *}$ & 34.112 & $0.000^{* *}$ & 0.971 & 0.450 \\
\hline
\end{tabular}

$* p<0.05 ; * * p<0.01$ 。

www.plant-ecology.com 

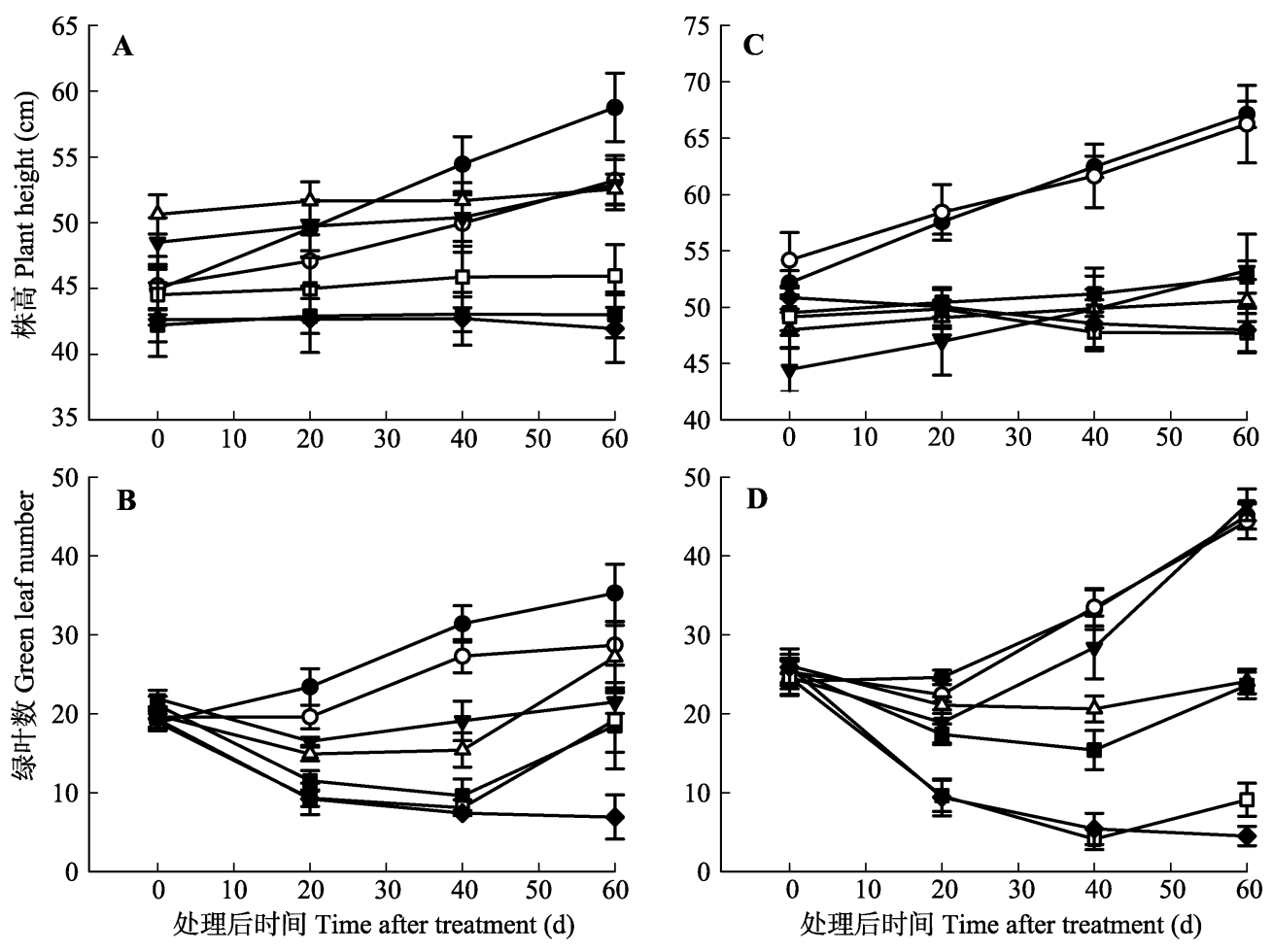

$$
\multimap \text { G0 } \multimap \text { G0.3 } \rightarrow \text { G0.6 } \rightarrow \text { G0.9 } \rightarrow \text { G1.2 } \neg-\text { G1.5 } \multimap \text { G1.8 }
$$

图1 不同时期喷施草甘膦后加拿大一枝黄花的形态指标(平均值沶准误差)。 A, B, 单种加拿大一枝黄花。 C, D, 混种加拿大 一枝黄花。G0、G0.3、G0.6、G0.9、G1.2、G1.5和G1.8同表1。

Fig. 1 The growth indices of Solidago canadensis after spraying glyphosate at different growth stages (mean $\pm S E$ ). A, B, S. canadensis grown in monoculture. C, D, S. canadensis grown in mixture. G0, G0.3, G0.6, G0.9, G1.2, G1.5 and G1.8 see Table 1.
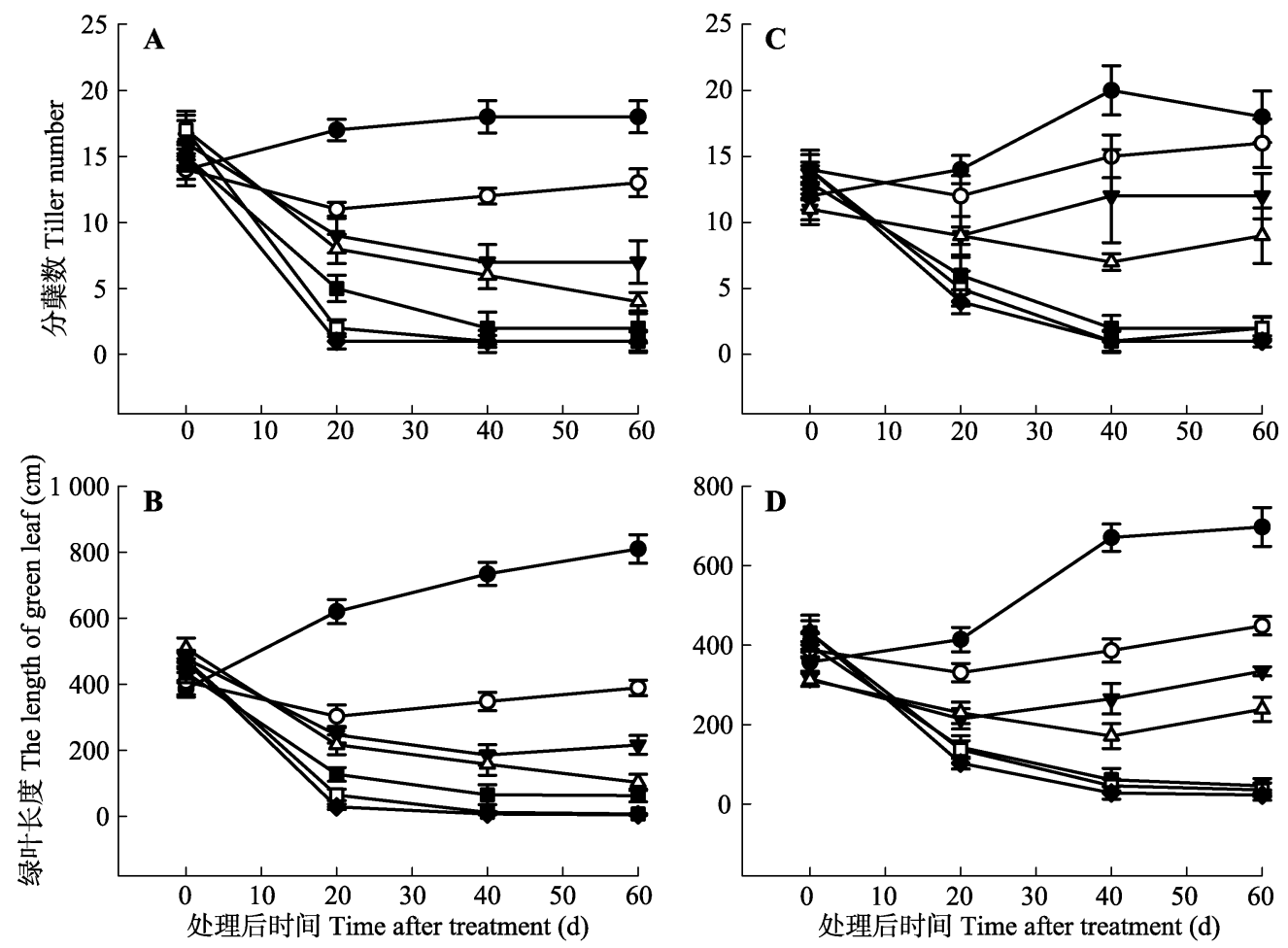

$\rightarrow \mathrm{G} 0 \multimap \mathrm{G} 0.3 \rightarrow \mathrm{G} 0.6 \sim \mathrm{G} 0.9$

$\mathrm{G} 0.9 \rightarrow \mathrm{G} 1.2 \rightarrow \mathrm{G} 1.5 \rightarrow \mathrm{G} 1.8$

图2 不同时期喷施草甘膦后白茅的形态指标(平均值土标准误差)。A, B, 单种白茅。C, D, 混种白茅。G0、G0.3、G0.6、G0.9、 G1.2、G1.5和G1.8同表1。

Fig. 2 The growth indices of Imperata cylindrica after spraying glyphosate at different growth stages (mean \pm SE). A, B, I. cylindrica grown in monoculture. C, D, I. cylindrica grown in mixture. G0, G0.3, G0.6, G0.9, G1.2, G1.5 and G1.8 see Table 1. 
植物的药效减小, 加拿大一枝黄花的绿叶数开始恢 复生长。白茅分苜的存活数和绿叶长度均随处理浓 度递增而不断减少, 喷药后第20天, 白茅植株地上 部分已大面积呈现发黄、枯萎等受害症状; 随着处 理时间延长, G0.3 (20-60天)处理下, 单种白茅的分 蓝数和绿叶长度呈增加趋势; 在G0.3、G0.6 (20-60 天)和G0.9 (40-60天)处理下混种白茅的分菜数和绿 叶长度也开始增加。

同样的，草甘膦处理显著抑制了加拿大一枝 黄花和白茅植株生物量的积累 $(p<0.05)$, 但对两 种植物根冠比的影响均不显著 $(p>0.05$, 表2)。随 处理浓度增加, 加拿大一枝黄花、白茅的地上茎 叶、地下部分积累的生物量均不断减少(图3B、3C, 图4B、4C)。

\section{2 种间竞争对加拿大一枝黄花和白茅生长的} 影响

混种条件下，植物种间竞争显著影响加拿大一
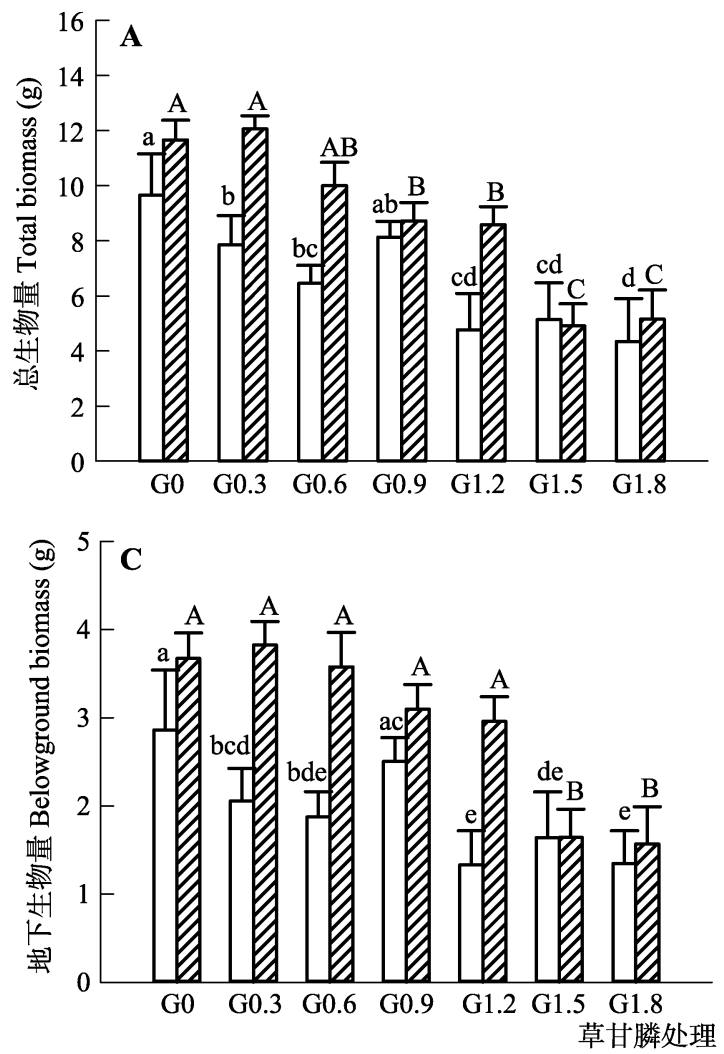

ZZ 混种加拿大一枝黄花 S. canadensis grown in mixture
枝黄花的株高增长、生物量积累以及根冠比, 但对 其绿叶数的影响不显著; 种间竞争同样显著影响白 茅的分藥和生物量的积累, 但对白茅的绿叶长度和 根冠比的影响不显著(表2)。对照组(G0)中, 混种加 拿大一枝黄花积累的生物量比单种加拿大一枝黄 花种群多20\%，而混种白茅积累的生物量比单种 白茅种群少 $6 \%$ (图3A，图4A); 存在种间竞争时， 加拿大一枝黄花同时提高其地上、地下部分生物 量的积累, 由此升高了植物的根冠比; 而白茅的 地上、地下部分生物量均减少，其根冠比并未发生 改变。随着草甘膦处理浓度增加, 只有G0.6处理下 单种、混种加拿大一枝黄花地下生物量以及G0.9 处理下单种、混种白茅地上、地下生物量之间差 异显著 $(p<0.05)$ 。种间竞争和草甘膦处理的交互 作用对加拿大一枝黄花株高增长、生物量积累，以 及白茅的分睬、生物量积累的影响均显著 $(p<0.05$, 表1)。
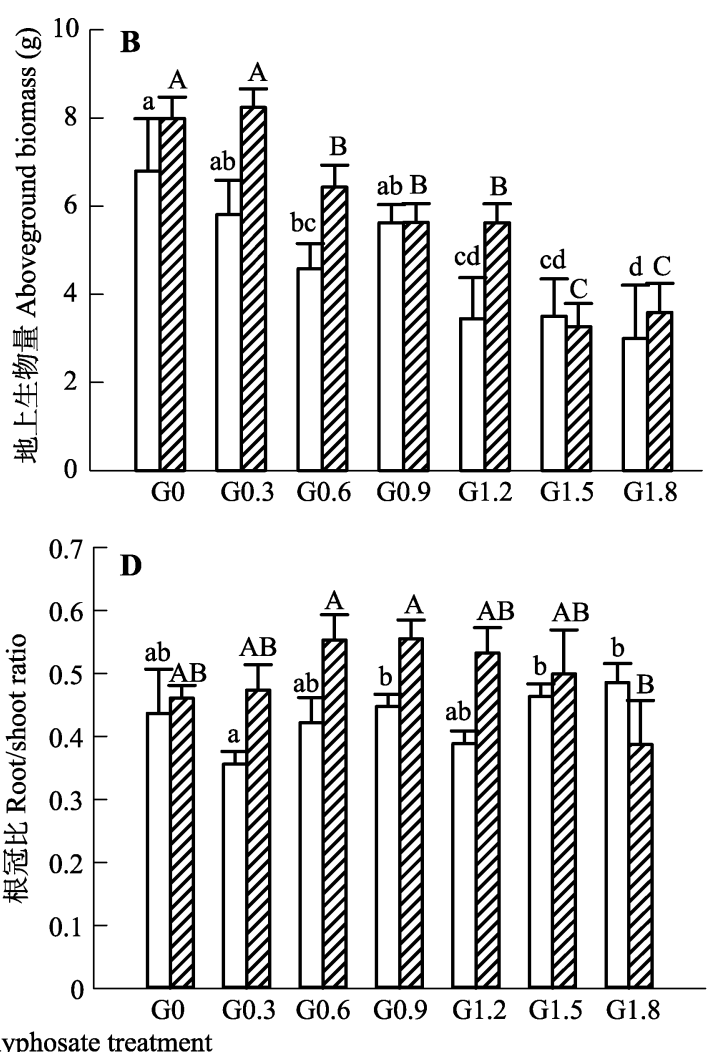

图3 不同草甘膦浓度处理对加拿大一枝黄花植株总生物量 $(\mathbf{A}) 、$ 地上生物量 $(\mathbf{B}) 、$ 地下生物量 $(\mathbf{C}) 、$ 根冠比 $(\mathbf{D})$ 的影响(平均值 \pm 标准误差)。不同小写、大写字母分别表示单种、混种植物在不同处理浓度之间的差异显著 $(p<0.05)$ 。 G0、G0.3、G0.6、G0.9、 G1.2、G1.5和G1.8同表1。

Fig. 3 Effects of different concentrations of glyphosate on total biomass (A), aboveground biomass (B), belowground biomass (C) and root/shoot ratio $(\mathbf{D})$ of Solidago canadensis (mean $\pm S E$ ). Different lowercase letters indicate that the indices are significantly different among different concentrations of glyphosate $(p<0.05)$ for plants grown in monocultures. Different uppercase letters indicate that the indices are significantly different among different concentrations of glyphosate $(p<0.05)$ for plants grown in mixtures. G0, G0.3, G0.6, G0.9, G1.2, G1.5 and G1.8 see Table 1.

www.plant-ecology.com 

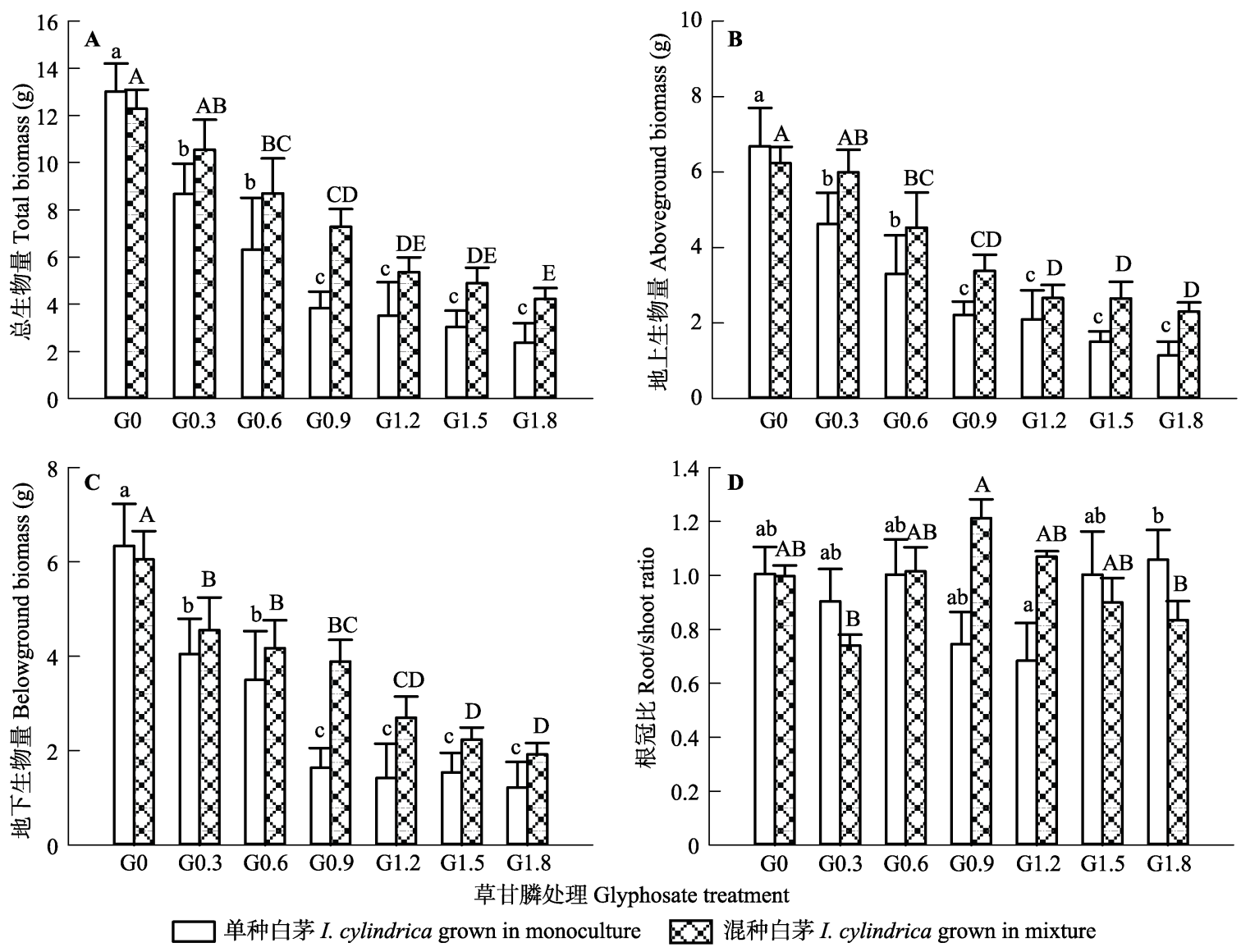

图4 不同草甘膦浓度处理对白茅植株总生物量(A)、地上生物量(B)、地下生物量 $(\mathbf{C}) 、$ 根冠比(D)的影响(平均值土标准误差)。 不同小写、大写字母分别表示单种、混种植物在不同处理浓度之间的差异显著 $(p<0.05)$ 。 G0、G0.3、G0.6、G0.9、G1.2、 G1.5和G1.8同表1。

Fig. 4 Effects of different concentrations of glyphosate on total biomass (A), aboveground biomass (B), belowground biomass (C) and root/shoot ratio (D) of Imperata cylindrica (mean $\pm S E$ ). Different lowercase letters indicate that the indices are significantly different among different concentrations of glyphosate $(p<0.05)$ for plants grown in monocultures. Different uppercase letters indicate that the indices are significantly different among different concentrations of glyphosate $(p<0.05)$ for plants grown in mixtures. G0, G0.3, G0.6, G0.9, G1.2, G1.5 and G1.8 see Table 1.

\section{3 草甘膦处理对加拿大一枝黄花和白茅种间竞 争关系的影响}

$R Y$ 表明两种植物种内、种间竞争能力的强弱。 如图5所示, 草甘膦处理显著影响了加拿大一枝黄 花和白茅的 $R Y(p<0.05)$, 对照组加拿大一枝黄花 的 $R Y$ 大于 1 , 表明在相同种植密度条件下, 加拿大 一枝黄花的种内竞争效应大于种间竞争效应, 加拿 大一枝黄花受到白茅的竞争影响较弱; 而白茅的 $R Y$ 小于 1 , 表明白茅的种间竞争强度大于种内竞争, 白 茅受到加拿大一枝黄花的竞争影响强烈。喷施草甘 膦后, 加拿大一枝黄花的 $R Y$ 呈现先升高后降低的趋 势(除G1.2组外), 白茅的 $R Y$ 也显示出相似的变化趋 势(除G1.8组外), 说明白茅对加拿大一枝黄花的竞 争力越来越弱, 其受到加拿大一枝黄花竞争的影响 也越来越弱。

\section{3 讨论}

种间竞争关系是生态学研究的重要领域, 当受 到环境压力、生物和非生物因素的干扰时，竞争关 系将会发生改变(黄秃等, 2012)。自然植物群落中不 同物种的竞争能力存在明显差别, 具有较大生长率 的物种往往成为竞争的优势者; 植物的大小特征是 反映植物相对竞争力的重要指标, 其中生物量是最 重要的参数(Keddy et al., 2002)。本试验的对照组中, 加拿大一枝黄花的种间竞争力要强于其种内竞争力 (图5), 因而混种加拿大一枝黄花的地上、地下部分 积累的生物量略大于单种加拿大一枝黄花, 而混种 白茅地上、地下生物量略小于单种白茅, 说明与土 著植物白茅相比, 作为成功入侵的外来植物, 加拿 大一枝黄花具有更强的资源竞争力(杨如意等, 2011; 

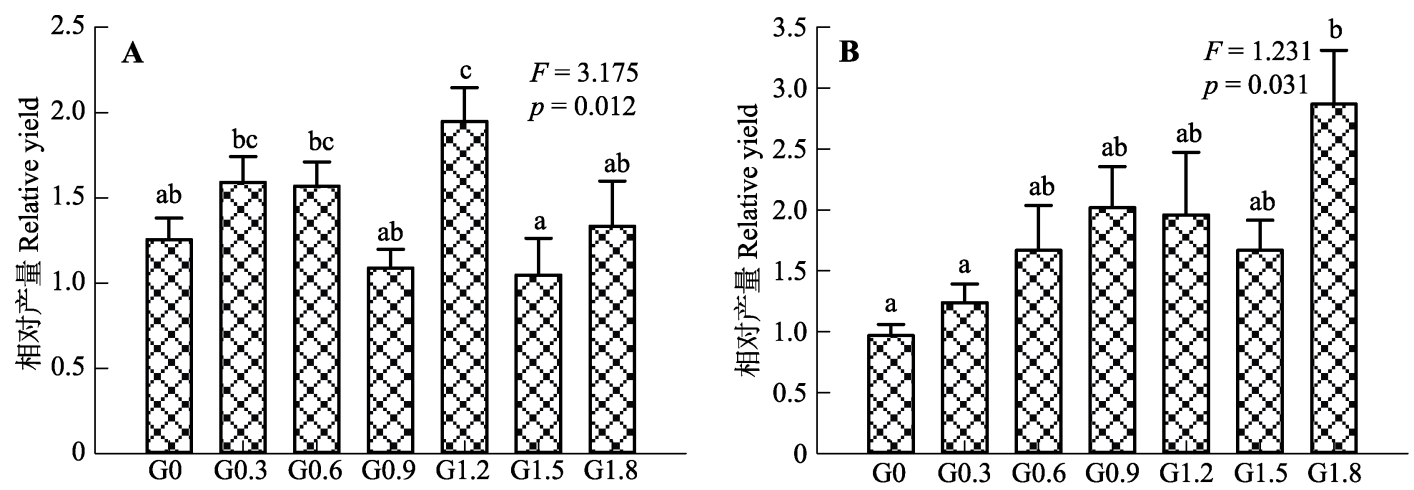

草甘膦处理 Glyphosate treatment

图5 不同浓度草甘膦处理对加拿大一枝黄花(A)和白茅(B)相对产量的影响(平均值土标准误差)。不同小写字母表示在不同处 理浓度之间差异显著 $(p<0.05)$ 。G0、G0.3、G0.6、G0.9、G1.2、G1.5和G1.8同表1。

Fig. 5 Effects of different concentrations of glyphosate on the relative yields of Solidago canadensis (A) and Imperata cylindrica (B) (mean $\pm S E$ ). Different lowercase letters indicate that relative yields are significantly different among different concentrations of glyphosate ( $p<0.05$ ). G0, G0.3, G0.6, G0.9, G1.2, G1.5 and G1.8 see Table 1.

陈㟁等, 2012)。

一般认为, 植物可通过塑造其表型特征和改变 生物量分配格局来实现对资源的竞争(朱强根等, 2013; 班芷华和王琼, 2015)。在与白茅相伴生长时, 加拿大一枝黄花通过迅速伸长其茎、增加绿叶数以 获取更多的光照资源, 积累更多的有机物质(图1), 从而抑制了伴生植物白茅的生长。本试验在花盆中 进行, 因而提供给植物生长的养分总量有限, 在土 壤养分和水分资源有限的环境中, 植物之间的竞争 主要集中在根系(平晓燕等, 2010)。存在种间竞争时, 加拿大一枝黄花自然群落有增加光合产物在地下器 官分配比例的趋势, 但白茅并没有显示改变其植株 生物量分配的迹象(图3D, 图4D), 混种群落中白茅 植株高度显著低于加拿大一枝黄花植株, 可能是因 为白茅受到了加拿大一枝黄花的光竞争胁迫, 导致 其有机物合成速率减慢, 短期内未能进行光合产物 的分配调控。

草甘膦是一种内吸广谱灭生性除草剂, 它可控 制全球危害最大的76种杂草(周垂帆等, 2013)。进入 植物体后草甘膦通过木质部和㓞皮部而传遍整株, 阻碍蛋白质的合成、引起次生代谢反应的失调, 从 而抑制植物的生长(王秀君等, 2008)。草甘膦处理对 白茅地上茎叶生长的抑制作用远高于对加拿大一枝 黄花的抑制作用(表1; 图3, 图4)。分藥是禾本科植 物与其他植物竞争的有效途径, 能为植株的生理代 谢提供能量, 增强其光合活性(彭恒等, 2010), 叶片 则是绿色植物进行光合作用合成有机物质的主要器 官。G1.2浓度处理后的第20天, 白茅分临的存活数
和绿叶片长度均低于 $50 \%$, 其光合活性大大受阻; 而同浓度处理下, 加拿大一枝黄花植株则仍有所增 长并且叶片枯萎率低于 $50 \%$ (图1, 图2)。作为以根状 茎进行营养繁殖的多年生草本植物, 加拿大一枝黄 花和白茅地下部分包含了植株的根系与地下茎, 草 甘膦处理对白茅地下生物量的影响同样高于对加拿 大一枝黄花的抑制作用(图3C, 图4C)。植物抗逆性 系指其对环境生物、非生物胁迫忍耐和抵御的能力, 不同种类植物因具有不同的生长发育调节、渗透调 节和代谢调节等生理功能(Chen et al., 2016), 对环 境胁迫的抵抗能力不同。本研究结果表明, 与土著 伴生植物白茅相比, 加拿大一枝黄花具有更大的生 理耐受性和更强的逆境抵抗能力。

植物之间最基本的相互作用是资源竞争和化 感作用(Thorpe et al., 2011), 植物只要共享某种生 存资源, 其种内个体或种间个体之间就会发生程度 不一的竞争。加拿大一枝黄花获取和利用资源的能 力要强于白茅, 在自然群落中, 白茅对加拿大一枝 黄花的竞争作用小于加拿大一枝黄花种内个体间的 相互竞争, 使得与白茅混种时, 加拿大一枝黄花植 株积累了更多的有机物质, 而白茅积累了较少的物 质。低浓度草甘膦影响了植物的种间竞争强度(图5), 混种加拿大一枝黄花和白茅地上、地下生物量积累 出现高于单种植株的趋势, 表明种内抑制作用逐渐 大于种间抑制。加拿大一枝黄花种内对地下有限资 源的竞争更为激烈, 因而其根冠比低于混种加拿大 一枝黄花的根冠比; 而白茅对草甘膦处理较敏感, 单种、混种时白茅整株均受到较大损伤。当受到环 
境胁迫时, 种间相互作用的类型和强度可能会随之 发生改变(Mullan et al., 2008)。草甘膦处理抑制加拿 大一枝黄花、白茅茎叶和根正常的生长发育, 降低 了两种植物地上部分竞争光照资源的能力, 以及地 下部分从环境吸收养分的能力, 由此减弱了两种植 物的种间竞争效应(图5)。作为一种环境胁迫因子, 草甘膦进入植物体内将会影响其分泌的次生代谢物 质, 从而改变植物的化感作用强度(Lydon \& Duke, 1988; 李光义等, 2010; Weidenhamer, 2010)。加拿大 一枝黄花是广为人知的具有强化感作用的入侵植物 (杨如意等, 2011; Wang et al., 2016), 在入侵过程中 会向环境中释放化感物质以抑制邻近植物的生长发 育, 还能促进有利于自身生长的根系微生物群落的 增长(Zhang et al., 2009; 杨柳青等, 2011), 由此增加 自身竞争能力。进入加拿大一枝黄花体内的草甘膦 很可能影响其根系分泌的具有化感效力的次生代谢 产物, 减弱了其对伴生植物白茅的化感抑制作用, 使得喷施草甘膦后混种白茅的生物量略比单种种 群高。

综合以上分析可知, 草甘膦处理显著抑制了加 拿大一枝黄花和白茅的生长, 生命力强的植物往往 对草甘膦胁迫具有更强的耐受性, 与本土植物白茅 相比, 入侵并成功定居、往外扩散的加拿大一枝黄 花对草甘膦的耐受性更强。喷施草甘膦减弱了两种 植物的种内、种间竞争强度, 可能是由于相邻植物 生长发育能力受抑制所致, 或者是由于加拿大一枝 黄花根系分泌的化感物质减少所致。基于试验结果, 建议在加拿大一枝黄花入侵前期, 避免使用草甘膦 进行防除, 以减小对土著白茅群落的影响。下一步 将在本研究的基础上, 进一步研究除草剂减弱种间 竞争关系的过程中何种因素在其中起主导作用。

基金项目国家林业公益性行业科研专项 (201404210)、国家自然科学基金(31400378)、浙江 省公益技术研究农业项目(2015C32011)、浙江省-中 国林业科学院科技合作重大项目(2015SY01)。

致谢 感谢中国林科院亚热带林业研究所刘月华、 赵林丽、陆琳莹在实验工作中给予的帮助。

\section{参考文献}

Bai SH, Ma FY, Hou D, Wang D (2010). Change in population niche during vegetation community succession in the Yellow River Delta. Chinese Journal of Eco-agriculture, 18, 581-587. (in Chinese with English abstract) [白世红, 马
风云, 侯栋, 王迪 (2010). 黄河三角洲植被演替过程种 群生态位变化研究. 中国生态农业学报, 18, 581-587.]

Ban ZH, Wang Q (2015). Responses of the competition between Alternanthera philoxeroides and Sambucus chinensis to simulated warming. Chinese Journal of Plant Ecology, 39, 43-51. (in Chinese with English abstract) [班芷 桦, 王琼 (2015). 喜旱莲子草和接骨草竞争对模拟增温 的响应. 植物生态学报, 39, 43-51.]

Brooker RW (2008). Facilitation in plant communities: The past, the present, and the future. Journal of Ecology, 95, 1-19.

Brooker RW (1998). The balance between positive and negative plant interactions and its relationship to environmental gradients: A model. Oikos, 81, 196-207.

Callaway RR (2002). Positive interactions among alpine plants increase with stress. Nature, 417, 844-848.

Chen JC, Zhang CX, Huang HJ, Wei SH, Zhang M, Guo F (2011). Sensitivity to glyphosate and dynamics of shikimate accumulation in three weed species following glyphosate application. Chinese Journal of Pesticide Science, 13, 471-474. (in Chinese with English abstract) [陈景超, 张朝贤, 黄红娟, 魏守辉, 张猛, 郭峰 (2011). 三种杂 草对草甘膦的敏感性及处理后植株体内莽草酸积累量 差异. 农药学学报, 13, 471-474.]

Chen JF, Xu HL, Sun YB, Huang LL, Zhang PX, Zou CP, Yu B, Zhu GF, Zhao CY (2016). Interspecific differences in growth response and tolerance to the antibiotic sulfadiazine in ten clonal wetland plants in South China. Science of the Total Environment, 543, 197-205.

Chen T, Liu WL, Zhang CB, Wang J (2012). Effects of Solidago canadensis invasion on dynamics of native plant communities and their mechanisms. Chinese Journal of Plant Ecology, 36, 253-261. (in Chinese with English abstract) [陈榇, 刘文莉, 张崇邦, 王江 (2012). 加拿大一 枝黄花入侵对本土植物群落动态的影响及其机制. 植 物生态学报, 36, 253-261.]

Dong M, Lu JZ, Zhang WJ, Chen JK, Li B (2006). Canada goldenrod (Solidago canadensis): An invasive alien weed rapidly spreading in China. Acta Phytotaxonomica Sinica, 44, 72-85. (in Chinese with English abstract) [董梅, 陆建 忠, 张文驹, 陈家宽, 李博 (2006). 加拿大一枝黄花一 一种正在迅速扩张的外来入侵植物. 植物分类学报, 44 , 72-85.]

Duke SO, Powles SB (2008). Glyphosate: A once-in-a-century herbicide. Pest Manage Science, 64, 319-325.

Funk JL, Cleland EE, Suding KN, Zavaleta ES (2008). Restoration through reassembly: Plant traits and invasion resistance. Trends in Ecology and Evolution, 23, 695-703.

Guo SL, Jiang HW, Fang F, Chen GQ (2009). Influences of herbicides, uprooting and use as cut flowers on sexual reproduction of Solidago canadensis. Weed Research, 49, 291-299. 
Gusev AP (2015). The impact of invasive Canadian goldenrod (Solidago canadensis L.) on regenerative succession in old fields. Russian Journal of Biological Invasions, 6(2), 7477.

He Q, Bertness MD, Altieri AH (2013). Global shifts towards positive species interactions with increasing environmental stress. Ecology Letters, 16, 695-706.

Huang QQ, Shen YD, Li XX, Cheng HT, Song X, Fan ZW (2012). Research progress on the distribution and invasiveness of alien invasive plants in China. Ecology and Environment Sciences, 21, 977-985. (in Chinese with English abstract ) [黄乔乔, 沈奕德, 李晓霞, 程汉亭, 宋 金金, 范志伟 (2012). 外来入侵植物在中国的分布及入侵 能力研究进展. 生态环境学报, 21, 977-985.]

Huang X, Li CJ, Nan ZB (2012). Competitive effects between Medicago sativa and Achnatherum inebrians. Acta Prataculturae Sinica, 21(1), 59-65. (in Chinese with English abstract) [黄秃, 李春杰, 南志标 (2012). 紫花苜宿与醉 马草的竞争效应. 草业学报, 21(1), 59-65.]

Ju RT, Li H, Shih CJ, Li B (2012). Progress of biological invasions research in China over the last decade. Biodiversity Science, 20, 581-611. (in Chinese with English abstract) [鞠瑞亭, 李慧, 石正人, 李博 (2012). 近十年中国生物 入侵研究进展. 生物多样性, 20, 581-611.]

Keddy P, Nielsen K, Weiher E (2002). Relative competitive performance of 63 species of terrestrial herbaceous plants. Journal of Vegetation Science, 13, 5-16.

Li GY, Hou XW, Deng X, Wang Z, Zhang GH, Li QF (2010). The effect on allelopathy of Wedelia chinensis Merr. resulting from herbicide. Chinese Agricultural Science Bulletin, 26(1), 173-181. (in Chinese with English abstract) [李光义, 侯宪文, 邓晓, 王中, 张桂花, 李勤奋 (2010). 除草剂对蜳蜞菊化感作用的影响研究. 中国农学通报, 26(1), 173-181.]

Liu WJ, Liu Y, Huang XQ, Zhou XQ, Song J, Yin Q, Wang D, Tao L, Zhang FL, Chang LJ, Zhang L, Lei SR (2012). Impact of spraying glyphosate on growth and yield component of glyphosate-tolerant soybean at different growth stages. Scientia Agricultura Sinica, 45, 675-684. (in Chinese with English abstract) [刘文娟, 刘勇, 黄小琴, 周西 全, 宋君, 尹全, 王东, 陶李, 张富丽, 常丽娟, 张蕾, 雷绍荣 (2012). 不同时期喷施草甘膦对抗草甘膦转基 因大豆生长和产量构成的影响. 中国农业科学, 45, 675-684.]

Lu Y, Sun GC, Zhu JY, Fan MJ, Mao HP (2006). Comparison of control effects of glyphosate application in different time on Solidago canadensis L. Weed Science, (1), 51-52. (in Chinese with English abstract) [陆彦, 孙国才, 朱建 亚, 范美娟, 毛慧萍 (2006). 草甘膦防除加拿大一枝黄 花不同时间用药效果比较. 杂草科学, (1), 51-52.]

Lydon J, Duke SO (1988). Glyphosate induction of elevated levels of hydroxybenzoic acids in higher plants. Journal of
Agricultural Food and Chemistry, 36, 813-818.

Maestre FT, Callaway RM, Fernando V, Lortie CJ (2009). Refining the stress-gradient hypothesis for competition and facilitation in plant communities. Journal of Ecology, 97, 199-205.

Mullan CC, Kristy K, Halpern BS (2008). Interactive and cumulative effects of multiple human stressors in marine systems. Ecology Letters, 11, 1304-1315.

Pan XB, Zhang JQ, Xu H, Zhang XL, Zhang W, Song HH, Zhu SF (2015). Spatial similarity in the distribution of invasive alien plants and animals in China. Natural Hazards, 77, 1751-1764.

Peng H, Gui FR, Li ZY, Li J, Wan FH (2010). Competition effect of Imperata cylindrical to Ageratina adenophora. Chinese Journal of Ecology, 29, 1931-1936. (in Chinese with English abstract) [彭恒，桂富荣，李正跃，李隽，万 方浩 (2010). 白茅对紫茎泽兰的竞争效应. 生态学杂 志, 29, 1931-1936.]

Ping XY, Zhou GS, Sun JS (2010). Advances in the study of photosynthetic allocation and its controls. Chinese Journal of Plant Ecology, 34, 100-111. (in Chinese with English abstract) [平晓燕, 周广胜, 孙敬松 (2010). 植物光合产 物分配及其影响因子研究进展. 植物生态学报, 34 , 100-111.]

Qiang S (2009). Weed Science. 2nd edn. Agricultural Press of China, Beijing. 1-6. (in Chinese) [强胜 (2009). 杂草学. 第二版. 中国农业出版社, 北京. 1-6.]

Qiang S, Chen GJ, Li BP, Meng L (2010). Invasive alien species in Chinese agricultural ecosystems and their management. Biodiversity Science, 18, 647-659. (in Chinese with English abstract) [强胜, 陈国奇, 李保平, 孟玲 (2010). 中国农业生态系统外来种入侵及其管理现状. 生物多 样性, 18, 647-659.]

Thorpe AS, Aschehoug ET, Atwater DZ, Callaway RM (2011). Interactions among plants and evolution. Journal of Ecology, 99, 729-740.

Wang CY, Xiao HG, Zhao LL, Liu J, Wang L, Zhang F, Shi YC, Du DL (2016). The allelopathic effects of invasive plant Solidago canadensis on seed germination and growth of Lactuca sativa enhanced by different types of acid deposition. Ecotoxicology, 25, 555-562.

Wang XJ, Lang ZH, Shan AS, Huang DF (2008). Advances in mechanism of herbicide in inhibiting amino acid biosynthesis and herbicide-tolerant transgenic plants. China Biotechnology, 28, 110-116. (in Chinese with English abstract) [王秀君, 郎志宏, 单安山, 黄大昉 (2008). 氨基 酸生物合成抑制剂类除草剂作用机理及耐除草剂转基 因植物研究进展. 中国生物工程杂志, 28, 110-116.]

Weidenhamer JR (2010). Direct and indirect effects of invasive plants on soil chemistry and ecosystem function. Journal of Chemical Ecology, 36, 59-69.

Williams AC, McCarthy BC (2001). A new index of interspecific

www.plant-ecology.com 
competition for replacement and additive designs. Ecological Research, 16, 29-40.

Xu ZH, Wang YP (2004). Disastrous mechanisms and control strategies of alien invasive plants. Chinese Journal of Ecology, 23, 124-127. (in Chinese with English abstract) [徐正浩, 王一平 (2004). 外来入侵植物成灾的机制及 防除对策. 生态学杂志, 23, 124-127.]

Yang LQ, Liao FY, Zhao K, Xu Q, Feng JS, Wu HQ (2011). The effects of different herbicide on the growth of Solidago canadensis. Journal of Central South University of Forestry \& Technology, 31(4), 109-113. (in Chinese with English abstract) [杨柳青, 廖飞勇, 赵坤, 许潜, 冯家生, 吴红强 (2011). 不同除草剂对加拿大一枝黄花生长的 影响. 中南林业科技大学学报, 31(4), 109-113.]

Yang RY, Zan ST, Tang JJ, Chen X (2011). Invasion mechanisms of Solidago canadensis L.: A review. Acta Ecologica Sinica, 31, 1185-1194. (in Chinese with English abstract) [杨如意, 冬树婷, 唐建军, 陈欣 (2011). 加拿大一枝黄花的入侵机理研究进展. 生态学报, 31, 1185-1194.]

Zhang RH (2010). Research on Screening of Replacement Plants for Flaveria bidentis and Competition Between Replacement Plants with F. bidentis. Master degree dissertation, Fujian Agriculture and Forestry University, Fuzhou. 12-37. (in Chinese with English abstract) [张瑞海 (2010). 黄顶菊替代植物的篮选及其与黄顶菊竞争效应的研究. 硕士学位论文, 福建农业大学, 福州. 12-37.]

Zhang SS, Jin YL, Tang JJ, Chen X (2009). The invasive plant Solidago canadensis L. suppresses local soil pathogens through allelopathy. Applied Soil Ecology, 41, 215-222.

Zhang WP, Jia X, Damagaard C, Baiy Y, Pan S, Wang GX (2013). The interplay between above- and below-ground plant-plant interactions along an environmental gradient: Insights from two-layer zone-of-influence models. Oikos, 122, 1147-1156.

Zhou CF, Li Y, Zhang XY, Yu YC (2013). Research advance in eco-toxicity of glyphosate. Ecology and Environment Sciences, 22, 1737-1743. (in Chinese with English abstract) [周垂帆, 李䒯, 张晓勇, 俞元春 (2013). 草甘膦毒性研 究进展. 生态环境学报, 22, 1737-1743.]

Zhou J, Li HL, Luo FL, Huang WJ, Zhang MX, Yu FH (2015). Effects of nitrogen addition on interspecific competition between Alternanthera philoxeroides and Alternanthera sessilis. Acta Ecologica Sinica, 35, 8258-8267. (in Chinese with English abstract) [周建, 李红丽, 罗芳丽, 黄文 军, 张明祥, 于飞海 (2015). 施氮对空心莲子草 (Alternanthera philoxeroides) 和莲子草 (Alternanthera sessilis)种间关系的影响. 生态学报, 35, 8258-8267.]

Zhu QG, Jin AW, Wang YK, Qiu YH, Li XT, Zhang SH (2013). Biomass allocation of branches and leaves in Phyllostachys heterocycla 'Pubescens' under different management modes: Allometric scaling analysis. Chinese Journal of Plant Ecology, 37, 811-819. (in Chinese with English abstract) [朱强根, 金爱武, 王意锟, 邱永华, 李 雪涛, 张四海 (2013). 不同营林模式下毛竹枝叶的生物 量分配: 异速生长分析. 植物生态学报, 37, 811-819.]

责任编委: 何维明 责任编辑: 王 蒇

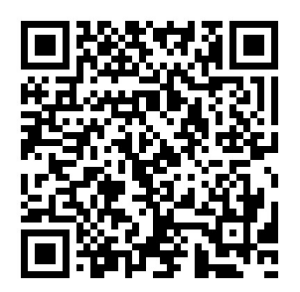

扫码向作者提问 